\title{
Comparative Study of Morbidity and Mortality between Different Types of Illicit Drug Abuse Overdose Cases Admitted to Poison Control Center Ain-Shams University Hospitals During 2014
}

\author{
Hend ElHelaly ${ }^{1}$, Hany Tawfik ${ }^{2}$ and Ahmed Shaban ${ }^{3}$
}

\footnotetext{
${ }^{1}$ Department of Forensic Medicine and Clinical Toxicology

${ }^{2}$ Poison Control Center Ain-Shams University Hospitals

$34^{\text {th }}$ grade undergraduate student ${ }^{3}$
}

Faculty of Medicine, Ain-Shams University, Cairo, Egypt.

\begin{abstract}
Background: There is a relatively limited new information data overall the global situation with regard to the prevalence of illicit drug abuse which in turn is considered a major medical problem.

Aim of the Work: The study aimed to highlight the magnitude of illicit drug abuse in Cairo, Egypt through investigating cases of illicit drug overdose presented to Poison Control Center Ain-Shams University Hospitals (PCCASUH) during 2014. In-addition, to compare the morbidities and mortalities between different illicit drug types among such cases.

Patients and Methods: A cross sectional hospital based study investigated all cases diagnosed as acute illicit drug abuse overdose presented to PCCASUH during 2014 including both addict and non-addict patients. Socio-demographic, clinical, and management data were collected analyzed and comparative study between different types of illicit drug abuse was done for all studied cases as regards morbidities and mortalities.

Results: The PCCASUH received 3022 cases of acute illicit drug abuse intoxications, 2291 were addict and 523 needed in-patient and ICU admission. Tramadol and benzodiazepine cases were more prevalent among illicit drug overdose followed by those diagnosed as methyl alcohol, cannabis and opiate and other opioids with male predominance. Morbidities and severity were more noticeable among cases of acute tramadol, opiate and other opioids and methyl alcohol overdose regarding cardiovascular, neurological and metabolic morbidities. Hence those cases mandated emergency treatment and intensive care department (ICU) admission. Deaths were more seen among cases of methyl alcohol, tramadol and opiate and other opioids overdose respectively.

Conclusions and Recommendations: Egyptian community suffer from a major problem of illicit drug abuse mainly among young adults males. The more prevalent drugs were tramadol followed by benzodiazepines, methyl alcohol, cannabis and opiate and other opioids. The study showed that opiate and other opioids, tramadol and methyl alcohol represented the most severe cases that developed different forms of morbidities and mandated emergency management and ICU admission. Egyptian Street need more integrated banning program between health, police and social workers against drug abuse. Inaddition, awareness campaigns between adolescents and young adults in clubs, schools and universities should be done.
\end{abstract}

\section{Introduction}

ubstance use disorder (SUD), defined as illicit drug
abuse, pharmaceutical drug misuse and $\checkmark$ dependence, and methyl alcohol abuse and dependence, is a complex public health problem affecting a diverse spectrum of different populations from all geographies, races, ethnicities, social classes, 
communities, and ages, with potential consequences across generations (Greenfield et., al. 2010).

However, there is a relatively limited new information needed overall the global situation with regard to the prevalence of illicit drug use which in turn considered a major medical problem (UNODC, 2014). Sweileh et., al. (2014) added that, illicit drug abuse and substance dependence, are present in all regions of the world including Middle Eastern Arab countries.

\section{Aim of the work}

This study aimed to highlight the magnitude of illicit drug abuse in Cairo, Egypt through investigating cases of illicit drug overdose presented to Poison Control Center Ain-Shams University Hospitals (PCCASUH) during 2014. In-addition, to compare different illicit drug types as regards morbidities and mortalities among those cases.

\section{Patients and Method}

The present study is a cross sectional hospital based study investigated cases presented with acute illicit drug abuse overdose including those presented with pharmaceutical misused including both addict and nonaddict patients. recorded:

For each patient, the following were

- The demographic (age, sex and residency) and clinical data (cardiovascular, neurological, hepatic, renal and metabolic complications), as well as mortalities associated with cases diagnosed as acute illicit drug abuse overdose). In-addition, management data in the form (emergency treatment, hospital admission, and hospital stay duration) were collected. All data collected were tabulated and statistically analyzed throughout the study period. Theses later findings were related to different types of illicit drug abuse overdose.

- A comparison was done between different types of illicit drug abuse overdose was done regarding morbidities and mortalities.

- Moreover, the clinical severity of each case was graded according to previously published criteria of Persson et al., (1998) who outline a standardized scale for poisoning severity grading that provides qualitative evaluation of morbidity, better identification of real risks and comparability of data. Grading was described as; (0): None, no symptoms or signs related to poisoning, (1): Mild, transient and spontaneously resolving symptoms, (2): Moderate, Pronounced or prolonged symptoms, and (3): Severe, or life-threatening symptoms and Death.

\section{Statistical analysis}

Statistical analysis was done using SPSS (Statistical Package for the Social Science) version 17, student (t) test and one way ANOVA test were used in-addition to the Least Significant Difference (LSD) was applied to estimate the intergroup difference. $\mathrm{P}<0.05$ for those numerical variables analyzed by ANOVA was considered significant and $X^{2}<0.05$ for qualitative and percentage values which analyzed by Chi-square and Fisher Exact test was also considered significant.

\section{Ethical consideration}

Informed consent was obtained from each patient or from their legal relative if they were unconscious and all data were kept confidential and anonymous. An ethical approval form Ethical Committee of Faculty of Medicine, Ain-Shams University as well as verbal approval form director of PCCASUH were taken.

\section{Results}

The PCCASUH received 3022 of acute illicit drug abuse overdose, 2291 were addict and 523 needed in-patient and ICU admission. The Prevalence of illicit drug abuse showed that, $(52 \%)$ of cases were tramadol overdose followed by benzodiazepines case were (16\%), methyl alcohol (methyl methyl alcohol) cases were (13\%), cannabis cases were (11\%), opiate and other opioids and other opioids cases were $(6 \%)$ and other pharmaceuticals misused as (Baclofen, tranquilizers, antidepressants, Cogentin and Nicotine) were the least prevalent and constituted (2\%) of cases (figures 1, 2 and 3).

Socio-demographic study revealed that age distribution showed non-significant difference between different types of drugs overdose (Tramadol, opiate and other opioids, benzodiazepines, methyl alcohol, cannabis and other pharmaceuticals misused) with mean age group was from 22 to 34 year old (Table 1). However sex and residency distribution showed significant difference when comparing different types of illicit drug abuse overdose cases. Male were the majority of all studied cases and opiate and other opioids was the most prevalent drug of abuse agent among males (94.3\%) followed by methyl alcohol (77.8\%), tramadol $(70.5 \%)$ and lastly benzodiazepines (58.7\%). Other pharmaceutical misused agents were more significantly prevalent among females (52.2\%) (Table 1). Urban cases presented with acute illicit drug abuse overdose were more than those presented from rural area and opiate and other opioids cases constituted (81\%), Methyl alcohol cases were $(77.8 \%)$ and tramadol cases were $(68.9 \%)$ and that was statistically significant (table $\mathbf{1}$ ).

Table (2) showed comparison between different types of illicit drug abuse overdose cases as regards morbidities and mortalities. There was significant difference as regards cardiovascular (shock and arrest), neurological (coma and convulsions) and acid base status disturbance (respiratory acidosis and alkalosis and metabolic acidosis and alkalosis). (11.3\%) of opiate and other opioids and other opioids and other opioids cases followed by (11.1\%) of methyl alcohol cases and (7\%) of tramadol cases suffered from shock, while there were three arrest cases diagnosed as acute tramadol overdose and two were diagnosed as acute opiate and other opioids overdose. Coma was significantly associated with benzodiazepines cases $(91.2 \%)$ followed by opiate and 
other opioids and other opioids cases (88.7\%) and tramadol $(68.8 \%)$ acute overdose cases. While seizures was significantly associated with tramadol cases $(11.1 \%)$. Although there was non-significant difference differences among cases of different types of illicit drug abuse overdose regarding both hepatic and renal dysfunction, $(27.7 \%)$ of tramadol cases, $(25 \%)$ of opiate and other opioids cases, (28\%) of methyl alcohol cases and $(12.5 \%)$ of benzodiazepine acute overdose suffered from hepatic dysfunction. Renal dysfunction was also seen in (30\%) of methyl alcohol, (17\%) benzodiazepines, (12.5) of tramadol and lastly (8.3\%) of opiate and other opioids acute overdose intoxicated cases.

Respiratory acidosis was significantly complicated opiate and other opioids overdose cases (69\%), followed by tramadol cases were $(48.1 \%)$ and benzodiazepines cases were $(22.4 \%)$ while, all cases of methyl alcohol overdose suffered from metabolic acidosis. Few tramadol cases suffered from respiratory alkalosis $(4.7 \%)$.

Hospital stay showed also significant difference on comparing different types of illicit drug abuse overdose with mean duration one to 5 days. The prolonged duration of stay were significantly evident among cases suffered from methyl methyl alcohol overdose followed by those presented with acute opiate and other opioids and tramadol overdose while least hospital stay was noticed among patients presented with acute benzodiazepines and cannabis overdose. Majority of acute opiate and other opioids (91.5\%) and tramadol (87\%) cases mandated ICU admission. (66.7\%) of methyl alcohol cases needed to be admitted to ICU, benzodiazepines cases mandated ICU admission were (30.4\%) and other cases with pharmaceuticals misused overdose were $(52.2 \%)$ and that was statistically different between different types of illicit drugs mentioned.
The table also showed that, there was significant difference between different types of illicit drug abuse overdose as regards death rates. The table also showed that, death commonly complicated cases of methyl alcohol toxicity (33.3\%) followed by cases of acute tramadol $(10.5 \%)$ and opiate and other opioids $(5.6 \%)$ overdose.

Table (3) showed that, there was significant difference between studied cases as regards clinical severity scoring presentations. Majority of severe cases were diagnosed as acute opiate and other opioids overdose (33.3\%) followed by those presented with acute tramadol overdose (14.2\%). However, majority of mild cases were seen among methyl alcohol cases (97.7\%), benzodiazepines (83.5\%) and cannabis (80.6\%).

Table (4) showed that there was significant difference between acute drug abuse overdose cases regarding emergency treatment needed in the form of oxygen supply, endotracheal intubation (ETT), dopamine infusion and sedative hypnotic administration. Oxygen supply and endotracheal intubation were needed in the emergency room among many cases of acute opiate and other opioids $(63.4,62 \%)$, and tramadol $(41.1,38.3 \%)$ overdose cases. Moreover, majority of cases with acute opiate and other opioids (80.5\%) and tramadol overdose (73.9\%) mandated mechanical ventilation while half of methyl alcohol and (25\%) of benzodiazepines cases needed mechanical ventilation. Dopamine infusion needed in majority of acute methyl alcohol overdose (75\%) followed by those presented with acute opiate and other opioids $(46.2 \%)$ and tramadol $(34 \%)$ overdose. Sedative hypnotics needed in half cases of acute tramadol overdose and majority of pharmaceutical misused cases (71.4\%).

Table (1): Chi-Square and ANOVA one way statistical analysis of some socio-demographic data among acute illicit drug abuse overdose cases admitted to PCCASUH during 2014

\begin{tabular}{|c|c|c|c|c|c|c|c|c|c|c|c|c|c|c|}
\hline \multirow{2}{*}{\multicolumn{2}{|c|}{$\begin{array}{l}\text { Socio- } \\
\text { Type of } \\
\text { Drug }\end{array}$}} & \multicolumn{2}{|c|}{ Tramadol } & \multicolumn{2}{|c|}{$\begin{array}{c}\text { opiate and } \\
\text { other opioids }\end{array}$} & \multicolumn{2}{|c|}{ Benzodiazepines } & \multicolumn{2}{|c|}{$\begin{array}{l}\text { methyl } \\
\text { alcohol }\end{array}$} & \multicolumn{2}{|c|}{ cannabis } & \multicolumn{2}{|c|}{ others } & \multirow[t]{2}{*}{$\begin{array}{c}\text { Chi- } \\
\text { square } \\
X^{2} \\
\end{array}$} \\
\hline & & $\mathrm{N}$ & $\%$ & $\mathrm{~N}$ & $\%$ & $\mathrm{~N}$ & $\%$ & $\mathrm{~N}$ & $\%$ & $\mathrm{~N}$ & $\%$ & $\mathrm{~N}$ & $\%$ & \\
\hline \multirow{2}{*}{ 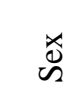 } & Male & 201 & 70.5 & 66 & 94.3 & 40 & 58. & 7 & 77.8 & 37 & 58.7 & 11 & 47.8 & \multirow[t]{2}{*}{$<0.001 *$} \\
\hline & Female & 84 & 29.5 & 4 & 5.7 & 29 & 42. & 2 & 22.2 & 26 & 41.3 & 12 & 52.2 & \\
\hline \multirow{2}{*}{ 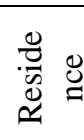 } & Rural & 85 & 31.1 & 12 & 19 & 28 & 40.6 & 2 & 22.2 & 20 & 33.3 & 9 & 42.9 & \multirow[t]{2}{*}{$<0.001 *$} \\
\hline & Urban & 188 & 68.9 & 51 & 81. & 41 & 59.4 & 7 & 77.8 & 40 & 66.7 & 12 & 57.1 & \\
\hline \multirow[b]{2}{*}{$\stackrel{8}{8}$} & & \multicolumn{2}{|c|}{ Mean \pm SD } & \multicolumn{2}{|c|}{ Mean \pm SD } & \multicolumn{2}{|c|}{ Mean \pm SD } & \multicolumn{2}{|c|}{ Mean \pm SD } & \multicolumn{2}{|c|}{ Mean \pm SD } & \multicolumn{2}{|c|}{ Mean \pm SD } & $\begin{array}{l}\text { ANOVA } \\
\mathrm{P} \text { value }\end{array}$ \\
\hline & & \multicolumn{2}{|c|}{$25.09 \pm 13.78$} & \multicolumn{2}{|c|}{$32.22 \pm 8.52$} & \multicolumn{2}{|c|}{$32.13 \pm 18.95$} & \multicolumn{2}{|c|}{$33.56 \pm 15.64$} & \multicolumn{2}{|c|}{$\begin{array}{c}30.10 \pm \\
4.7\end{array}$} & \multicolumn{2}{|c|}{$22.43 \pm 13.1$} & $<0.06$ \\
\hline
\end{tabular}

Chi-Square for Qualitative \% variables and $* X^{2}<0.05=$ significant ANOVA one way statistical analysis for numerical variables and $* P<0.05=$ significant. 
Table (2): Fisher Exact test and ANOVA one way statistical analysis of morbidities and mortalities among acute drug of abuse overdose cases during 2014

\begin{tabular}{|c|c|c|c|c|c|c|c|c|c|c|c|c|c|c|}
\hline \multirow{2}{*}{\multicolumn{2}{|c|}{$\begin{array}{c}\text { Clinical } \\
\text { data }\end{array}$}} & \multicolumn{2}{|c|}{ tramadol } & \multicolumn{2}{|c|}{$\begin{array}{c}\text { opiate and } \\
\text { other } \\
\text { opioids } \\
\end{array}$} & \multicolumn{2}{|c|}{$\begin{array}{c}\text { Benzodiaz } \\
\text { epines }\end{array}$} & \multicolumn{2}{|c|}{$\begin{array}{l}\text { methyl } \\
\text { alcohol }\end{array}$} & \multicolumn{2}{|c|}{ cannabis } & \multicolumn{2}{|c|}{ others } & \multirow{2}{*}{$\begin{array}{c}\begin{array}{c}\text { Fisher } \\
\text { Exact }\end{array} \\
\mathbf{X}^{2}\end{array}$} \\
\hline & & $\mathbf{N}$ & $\%$ & $\mathbf{N}$ & $\%$ & $\mathbf{N}$ & $\%$ & $\mathbf{N}$ & $\%$ & $\mathbf{N}$ & $\%$ & $\mathbf{N}$ & $\%$ & \\
\hline \multicolumn{2}{|c|}{ ICU admission } & 224 & 78.0 & 65 & 91.5 & 21 & 30.4 & 6 & 66.7 & 4 & 6.3 & 12 & 52.2 & $<0.001^{*}$ \\
\hline \multirow{3}{*}{ 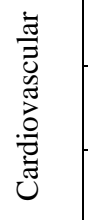 } & Normal & 242 & 84 & 50 & 70 & 64 & 93 & 8 & 88 & 63 & 10 & 22 & 95.7 & \multirow{3}{*}{$<0.001 *$} \\
\hline & Shock & 21 & 7.3 & 8 & 11.3 & 0 & 0.0 & 1 & 11.1 & 0 & 0.0 & 0 & 0.0 & \\
\hline & Arrest & 3 & 1.0 & 2 & 2.8 & 0 & 0.0 & 0 & 0.0 & 0 & 0.0 & 0 & 0.0 & \\
\hline \multirow{2}{*}{$\stackrel{\bar{D}}{:}$} & Normal & 34 & 72.3 & 12 & 75. & 7 & 87.5 & 1 & 20. & 0 & 0.0 & 1 & 100 & \multirow{2}{*}{0.103} \\
\hline & Dysfunction & 13 & 27.7 & 4 & 25.0 & 1 & 12.5 & 4 & 28 & 0 & 0.0 & 0 & 0.0 & \\
\hline \multirow{2}{*}{ 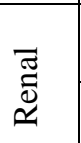 } & Normal & 70 & 87.5 & 22 & 91.7 & 10 & 83.3 & 3 & 60 & 0 & 0.0 & 1 & 100. & \multirow{2}{*}{0.342} \\
\hline & Dysfunction & 10 & 12.5 & 2 & 8.3 & 2 & 17 & 2 & 30.0 & 0 & 0.0 & 0 & 0.0 & \\
\hline \multirow{3}{*}{ 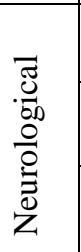 } & Normal & 56 & 19.8 & 8 & 11.3 & 6 & 8.8 & 6 & 66.7 & 7 & 11.1 & 8 & 34.8 & \multirow{3}{*}{$<0.001 *$} \\
\hline & Coma & 192 & 68.8 & 63 & 88.7 & 62 & 91.2 & 5 & 25.0 & 16 & 28.9 & 13 & 59.1 & \\
\hline & Seizers & 31 & 11.1 & 0 & 0.0 & 0 & 0.0 & 0 & 0.0 & 0 & 0.0 & 1 & 4.5 & \\
\hline \multirow{6}{*}{ 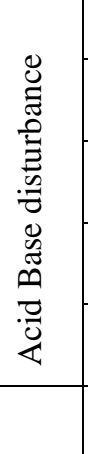 } & Normal & 55 & 25.9 & 12 & 20.7 & 34 & 69.4 & 0 & 0.0 & 21 & 77.8 & 10 & 76.9 & \multirow{5}{*}{$<0.001 *$} \\
\hline & $\begin{array}{l}\text { Metabolic } \\
\text { Acidosis }\end{array}$ & 44 & 20.8 & 4 & 6.9 & 2 & 4.1 & 8 & 100 & 4 & 14.8 & 0 & 0.0 & \\
\hline & $\begin{array}{l}\text { Metabolic } \\
\text { Alkalosis }\end{array}$ & 1 & 0.5 & 0 & 0.0 & 1 & 2.0 & 0 & 0.0 & 0 & 0.0 & 0 & 0.0 & \\
\hline & $\begin{array}{l}\text { Respiratory } \\
\text { Acidosis }\end{array}$ & 102 & 48.1 & 40 & 69.0 & 11 & 22.4 & 0 & 0.0 & 2 & 7.4 & 2 & 15.4 & \\
\hline & $\begin{array}{l}\text { Respiratory } \\
\text { Alkalosis }\end{array}$ & 10 & 4.7 & 2 & 3.4 & 1 & 2.0 & 0 & 0.0 & 0 & 0.0 & 1 & 7.7 & \\
\hline & Deaths & 30 & 10.5 & 4 & 5.6 & 0 & 0.0 & 3 & 33.3 & 0 & 0.0 & 1 & 4.3 & $<0.001 *$ \\
\hline \multirow{2}{*}{ 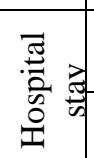 } & & \multicolumn{2}{|c|}{ Mean \pm SD } & \multicolumn{2}{|c|}{ Mean \pm SD } & \multicolumn{2}{|c|}{$\mathrm{Mea} \pm \mathrm{SD}$} & \multicolumn{2}{|c|}{ Mean \pm SD } & \multicolumn{2}{|c|}{ Mean \pm SD } & \multicolumn{2}{|c|}{ Mean \pm SD } & $\begin{array}{c}\text { ANOVA } \\
\mathrm{P} \text { value }\end{array}$ \\
\hline & & \multicolumn{2}{|c|}{$2.08 \pm 2.61$} & \multicolumn{2}{|c|}{$2.25 \pm 2.40$} & \multicolumn{2}{|c|}{$1.54 \pm 0.78$} & \multicolumn{2}{|c|}{$4.89 \pm 5.28$} & \multicolumn{2}{|c|}{$1.08 \pm 0.27$} & 1.57 & 0.79 & $<0.001 *$ \\
\hline
\end{tabular}

Fisher Exact test for Qualitative \% variables and $* X^{2}<0.05=$ significant ANOVA one way statistical analysis for numerical variables and $* P<0.05=$ significant. 
Table (3): Fisher Exact test of clinical severity scoring among acute illicit drug abuse overdose cases admitted to PCCASUH during 2014 according to Person et., al. 1998

\begin{tabular}{|c|c|c|c|c|c|c|c|c|c|c|c|c|c|}
\hline \multirow{2}{*}{$\begin{array}{l}\begin{array}{r}\text { Type of } \\
\text { Drug }\end{array} \\
\text { Clinical } \\
\text { data }\end{array}$} & \multicolumn{2}{|c|}{ tramadol } & \multicolumn{2}{|c|}{$\begin{array}{c}\text { opiate and other } \\
\text { opioids }\end{array}$} & \multicolumn{2}{|c|}{ BZD } & \multicolumn{2}{|c|}{$\begin{array}{l}\text { methyl } \\
\text { alcohol }\end{array}$} & \multicolumn{2}{|c|}{ cannabis } & \multicolumn{2}{|c|}{ others } & $\begin{array}{c}\text { Fisher } \\
\text { Exact } \\
\mathbf{X}^{2} \\
\end{array}$ \\
\hline & $\mathrm{N}$ & $\%$ & $\mathrm{~N}$ & $\%$ & $\mathrm{~N}$ & $\%$ & $\mathrm{~N}$ & $\%$ & $\mathrm{~N}$ & $\%$ & $\mathrm{~N}$ & $\%$ & \\
\hline Mild & 1293 & 81.8 & 124 & 63.6 & 434 & 83.5 & 38 & 97.7 & 262 & 80.6 & 367 & 88 & \\
\hline Moderate & 63 & 4 & 6 & 3.1 & 59 & 11.3 & 3 & 0.8 & 59 & 18.2 & 10 & 7 & $<0.001$ \\
\hline Severe & 224 & 14.2 & 65 & 33.3 & 27 & 5.2 & 6 & 1.5 & 4 & 1.2 & 0 & 0 & \\
\hline
\end{tabular}

Fisher Exact test for qualitative percentage variables and $* X^{2}<0.05=$ significant

Table (4): Chi-square statistical analysis of types of emergency treatment needed to acute drug of abuse overdose cases during 2014

\begin{tabular}{|c|c|c|c|c|c|c|c|c|c|c|c|c|c|}
\hline \multirow{2}{*}{$\begin{array}{l}\text { Type of Drug } \\
\text { Clinical } \\
\text { data }\end{array}$} & \multicolumn{2}{|c|}{ tramadol } & \multicolumn{2}{|c|}{$\begin{array}{c}\text { opiate and } \\
\text { other } \\
\text { opioids }\end{array}$} & \multicolumn{2}{|c|}{$\begin{array}{c}\text { Benzodia } \\
\text { zepines }\end{array}$} & \multicolumn{2}{|c|}{$\begin{array}{l}\text { methyl } \\
\text { alcohol }\end{array}$} & \multicolumn{2}{|c|}{ cannabis } & \multicolumn{2}{|c|}{ others } & \multirow[t]{2}{*}{$\begin{array}{c}\text { Chi- } \\
\text { square } \\
\mathbf{X}^{2} \\
\end{array}$} \\
\hline & $\mathrm{N}$ & $\%$ & $\mathrm{~N}$ & $\%$ & $\mathrm{~N}$ & $\%$ & $\mathrm{~N}$ & $\%$ & $\mathrm{~N}$ & $\%$ & $\mathrm{~N}$ & $\%$ & \\
\hline oxygen & 118 & 41.1 & 45 & 63.4 & 7 & 10. & 4 & 44 & 1 & 1.6 & 3 & 13.0 & $<0.001 *$ \\
\hline ETT & 110 & 38.3 & 44 & 62.0 & 2 & 2.9 & 5 & 56 & 0 & 0.0 & 2 & 8.7 & $<0.001^{*}$ \\
\hline $\begin{array}{l}\text { Mechanical } \\
\text { Ventilation }\end{array}$ & 82 & 73.9 & 33 & 80.5 & 2 & 25 & 4 & 50. & 0 & 0.0 & 2 & 10 & $<0.001 *$ \\
\hline Dopamine & 33 & 34.0 & 12 & 46.2 & 0 & 0.0 & 3 & 75 . & 0 & 0.0 & 1 & 14.3 & $0.044 *$ \\
\hline Sedative hypnotics & 56 & 57.7 & 2 & 6.2 & 0 & 0 & 0 & 0.0 & 0 & 0 & 5 & 71.4 & $0.007 *$ \\
\hline
\end{tabular}

Chi-square test for qualitative percentage variables and $* X^{2}<0.05=$ significant

Figure 1:Shows the percentage of addict patients among acute illicit drug abuse overdose cases admitted to PCCASUH during 2014

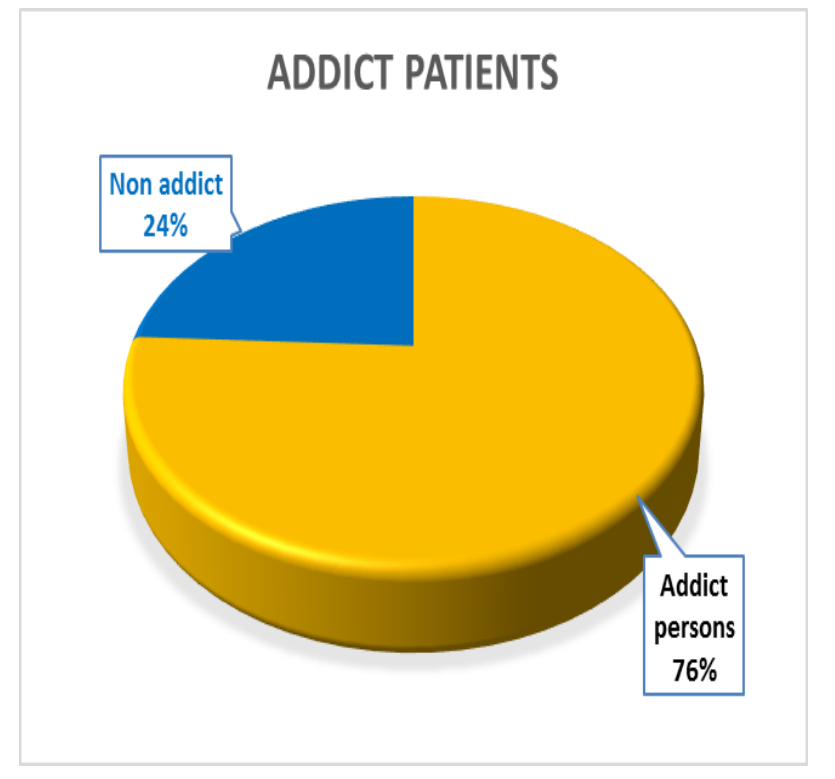

Figure 2: Shows the percentage of patients admitted to ICU and those admitted to In-patient department among acute illicit drug abuse overdose cases admitted to PCCASUH during 2014

Site of Addmission

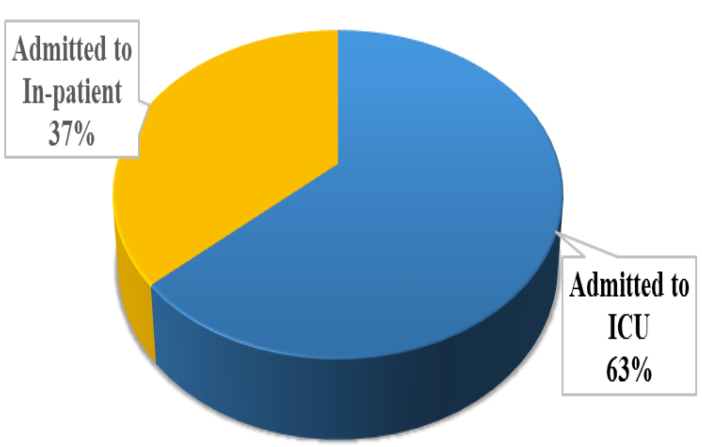

Ⓐdmitted to ICU $\square$ Admitted to In-patient 
Figure 3:Shows the prevalence of different type of illicit drug abuse overdose among cases admitted to PCCASUH during 2014

\section{Prevelance of illicit drug}

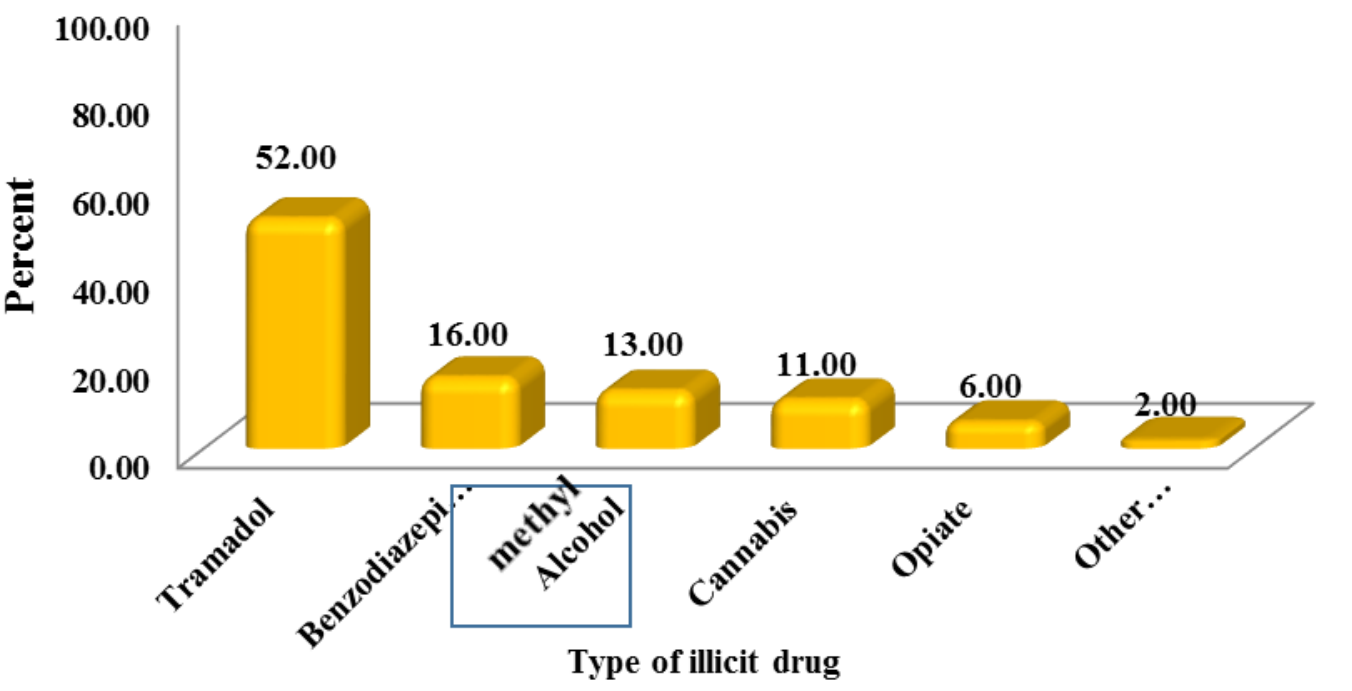

\section{Discussion}

Illicit drug abuse is a worldwide problem with serious consequences for the individual and society. The increase in illicit drug abuse overdoses is the leading cause of injury death in the United States. It is attributable primarily to the misuse and abuse of prescription drugs, especially opioid analgesics, sedatives/tranquilizers, and stimulants (Paulozzi et al., 2015).

Injecting drug abuse seems to be a similar health problem in magnitude in Iceland as in other Scandinavian countries (Sigvaldason et. al., 2014). Prescription drug abuse, including benzodiazepines, is a growing health problem in Japan (Shimane et., al. 2014). Sweileh et., al. (2014) added that, substance use disorders, which include illicit drug abuse and substance dependence, are present in all regions of the world including Middle Eastern Arab countries.

This study highlighted the magnitude of illicit drug abuse in Cairo, Egypt through investigating some socio-demographic and clinical data of cases presented to PCCASUH with acute illicit drug abuse overdose during 2014. United Nation's joint program on HIV and AIDS in (2004) annual report had declared that, drug addiction is one of the serious problems that worry the Egyptian government, as it affects young people within the age of work and productivity (UNAIDS, 2004). Fawzi, (2011) added that, drug abuse overdose is a wide range problem in Egypt and tramadol is the most prevalent one among cases admitted to PCCASUH during (2010).

The PCCASUH received 3022 of acute illicit drug abuse overdose during 2014; majority were addict and one fifth of them needed in-patient and ICU admission. The study also showed that, tramadol represented most of cases followed by benzodiazepines cases, methyl alcohol cases, cannabis cases, opiate and other opioids cases and lastly pharmaceuticals misused drugs as (Baclofen, tranquilizers, antidepressants, cogentin and nicotine) were the least prevalent cases. This goes parallel with study of Fawzi, (2011) who showed that tramadol is a widely distributed in Egypt and he postulated that to the illegal transactions of tramadol that made it easily accessible and readily provided at cheap cost despite of it being scheduled. In-addition, El Masry and Tawfik (2013), recorded that tramadol was the most involved agent constituted $7.4 \%$ of the total poisoning cases admitted to PCCASUH during (2013). They also added that methanol poisoning presentation were decreased by about $75 \%$ due to the state's tighter control against alcoholic beverages adulteration. Tawfik and ElHelaly, (2015) reported that about one third of patients admitted to PCCASUH during 2013 were diagnosed as illicit drug abuse and pharmaceutical misused overdose and tramadol as well as cannabis were the most prevalent cases.

In-contrary, UNODC, (2011) global annual survey found cannabis is by far the most widely used illicit drug type, consumed by between 125 and 203 million people worldwide in 2009 followed by amphetamine, opioids (including opium, heroin and prescription opioids) and cocaine. Moreover, Amr et., al . (2014) study revealed that, cannabis was the most common drug abused for $3.6 \%$ of patients followed by 
tramadol and poly-substance overdose cases presented to emergency department of Mansours University hospitals.

The study recorded some socio-demographic data, with relation to different types of illicit drug abuse; age distribution revealed that mean age group were from 22- 35 among cases presented with acute illicit drug abuse overdose and that was non-significantly different between different types.This was in accordance with NSDUH, (2010) report which declared that, illicit drug dependence or abuse was greater among adults aged 18 or older in United States during 2010. Moreover, Amr et., al. (2014) recorded cases with substance abuse overdose presented to emergency department of Mansours University were younger than 30 years old and they added that most of them were addict.

The sex distribution showed significant difference when comparing different types of illicit drug abuse overdose. The study showed that male predominated majority of cases for all types except for pharmaceuticals misused overdose, female were more predominant. This goes parallel with El-Sawy et., al. (2010) study at Delta Nile population, Tanata University, Egypt who stated that, males represented the majority of cases $(70 \%)$ presented with acute illicit drug abuse overdose, however, females were $(30 \%)$ of cases. UNODC, (2011) global annual survey at (2011) concluded that most of drug abuses was more prevalent among males than females except for amphetamine where female were more prevalent. National Institute of Drug Abuse at (2010) in United States of America (USA) stated that females more likely to misuse controlled prescribed drug than males and attributed that to the accessibility of prescribed psychoactive substance from nearby market (NIDA, 2011).

This gender predilection was explained by Afifi, (2007) who stated that gender-based differences in drug abuse may emanate from a biomedical (genetic, hormonal, anatomical and physiological) and psychosocial factors. Moreover, El-Sawy, (2010) study showed that males started drug use earlier than females and had longer duration of dependence compared to females. They postulated that to the motives for drug use in males were found to be peer pressures, seeking pleasure, to improve mood and to improve sex and to show masculinity in descending order.

Most of the studied cases came from urban area $(75 \%)$ while those from rural area were $(25 \%)$ of the cases and that was significantly different when comparing different types of illicit drug abuse overdose with opiate and other opioids represented the majority of cases came from urban places (81\%). El-Sawy et., al. (2010) stated that most of studied cases with substance abuse were from Great Cairo and most of them were addicts. UNODC, (2011) annual survey found that, higher prevalence of substance abuse was among the urban population. SAMHSA, (2013) report presents a detailed National Survey on Drug Use and Health (NSDUH), (2013) annual survey of the civilian, noninstitutionalized population of the United States. They postulated residency difference findings to the diversity between both urban and rural communities regarding, socioeconomic, educational and professional values.

The study also showed comparison between different types of illicit drug abuse overdose cases as regards morbidities and mortalities. There was significant difference between different types as regards cardiovascular (shock and arrest), neurological (coma and convulsions) and acid base status disturbance (respiratory acidosis and alkalosis and metabolic acidosis and alkalosis). Pateria et., al. (2013) recorded adverse cardiovascular, neurological, renal and psychiatric consequences associated with various illicit substance abuse among cases admitted to Sir Charles Gairdner Hospital.

Opiate and other opioids cases constituted most of cases who suffered from shock followed by those diagnosed as acute methyl alcohol and tramadol overdose cases. Moreover, there were two arrest cases among acute opiate and other opioids overdose and three were diagnosed as acute tramadol overdose. This goes parallel with NIDA, (2012), USA report found a connection between the abuse of most drugs and adverse cardiovascular effects, ranging from abnormal heart rate to heart attacks. Injection drug abuse can also lead to cardiovascular problems such as collapsed veins and bacterial infections of the blood vessels and heart valves.

Daubin et., al. (2007) reported cases of acute tramadol overdose who developed a ventricular tachycardia, followed by a brief cardiac arrest with refractory shock. Elkalioubie et., al. (2011) attributed that, to, excessive blood epinephrine levels due to the inhibition of norepinephrine reuptake in tramadol overdose.

Moreover, Fareed et., al. (2011) investigated heroin and other opioids cardio-toxic effect he stated many cardiovascular morbidities have been reported in overdose. Cardiotoxic effect of opiates and other opioids was explained by Benyamin et., al. (2008) who stated that opiate associated with histamine release and consequent vasodilation and hypotension. Moreover, Parasympathetic stimulation may also contribute to bradycardia. In-contrary, Leffler et., al. (2012) postulated fatal cardiotoxic effect of opioids to the inhibitors of voltage-gated $\mathrm{Na}^{+}$channels on myocardium.

Jann et., al. (2014) added that, benzodiazepines overdose might result in cardiac dysrhythmias and arrest. Greller and Gupta, (2015) attributed this cardiotoxic effect complicating benzodiazepines overdose to the enhancement effect of the neurotransmitter gamma- 
aminobutyric acid (GABA) with CNS depression with subsequent vasomotor center depression and consequently cardiac arrest.

The study reported that, coma was significantly associated with most of benzodiazepines overdose cases followed by opiate and other opioids cases and tramadol acute overdose cases. While seizures was seen mainly among tramadol overdose cases. This was in agreement with NIH, (2012) report who stated that, all drugs of abuse act in the brain to produce their euphoric effects; however some of them also have severe negative consequences in the brain such as seizures, stroke, and widespread brain damage that can impact all aspects of daily life. Moreover, Brust, (2014) recorded neurological complications of varies drug of abuse include opioids, psychostimulants, marijuana and related agents, sedatives, hallucinogens, inhalants, phencyclidine and related agents, and anticholinergics including loss of consciousness and seizures.

Tashakori and Afshari, (2010) stated that, tramadol overdose impairs consciousness and may induce EEG changes and convulsions. They postulated convulsions to its serotonergic action. WHO, (2014) stated that the depressant effect of tramadol is due to its pharmacological action like opioids on $\mathrm{Mu}$ receptors mediating CNS depression.

Boyer, (2012) postulated opioid effects on central nervous system to the mu opioid receptor binding which is responsible for the preponderance of depressant clinical effects caused by opioids. Greller and Gupta, (2015) attributed benzodiazepines depressant effect to the enhancement of the neurotransmitter gammaaminobutyric acid (GABA) with CNS depression

Although there was non-significant difference differences among studied cases of different illicit drug abuse overdose regarding both hepatic and renal dysfunction. Quarter of tramadol cases, opiate and other opioids, methyl alcohol and one fifth of benzodiazepine acute overdose cases suffered from hepatic dysfunction. Renal dysfunction was also seen in third of methyl alcohol cases, followed by benzodiazepines, tramadol and lastly opiate and other opioids acute overdose cases. This goes parallel with Boyer, (2012) postulated renal failure that might be associated with opiates to the coma induces prolonged bed ridden immobilization with resultant rhabdomyolysis complicated with myoglobinurea. In-addition, Pateria et., al. (2013) postulated tramadol induced acute kidney injury to associated seizures that resulted in rhabdomyolysis.

Vengeliene et., al. (2008) showed that methyl alcohol overdose cases suffered from acute renal failure. This was explained by Verhelst et., al. (2004) who stated that, although the kidney is not the target organ of methanol toxicity, it may lead to hydrobic degeneration of tubular epithelium with sparing of glomerular one.

Pateria et., al. (2013) study who stated that illicit drug abuse can cause a range of liver abnormalities ranging from asymptomatic derangement of liver function tests to fulminant hepatic failure and more commonly associated with cannabis use. Swarnalatha et., al. (2013) attributed that to the direct toxic effect of the metabolite delta-9-THC (tetrahydrocannabinol) on hepatocytes.

Most of opiate and other opioids overdose cases suffered from respiratory acidosis, followed by half of tramadol cases and quarter of benzodiazepines acute overdose cases while, all cases of methyl alcohol overdose suffered from metabolic acidosis and that was significantly difference on comparing different types of illicit drugs. Henry, (2000) stated that, metabolic consequences of drug misuse are uncommon, but are increasing as illicit drug use becomes more widespread and most commonly occur with heroin. Sharma et., al. (2011) stated that, in-addition to formic acid accumulation; significant metabolic acidosis complicating acute methanol ingestion could be attributed to, low serum bicarbonate level and the increased anion gap secondary to high lactate and ketone level. Boyer, (2012) postulated respiratory depression with subsequent respiratory failure and acidosis complicated opioids overdose to the depression of central nervous system as a result of mu opioid receptor binding.

Hospital stay duration showed also significant difference when comparing different types of illicit drug abuse overdose with mean duration of stay was from one to 5 days. The prolonged duration of stay were evident among cases suffered from methyl alcohol overdose followed by those presented with acute opiate and other opioids and tramadol overdose while least hospital stay was noticed among patients presented with acute benzodiazepines and cannabis overdose. In-addition, majority of acute opiate and other opioids and tramadol overdose cases mandated ICU admission. More than half of methyl alcohol cases needed to be admitted to ICU, while half of pharmaceuticals misused and one third of benzodiazepines cases needed to be admitted at ICU.

Cheryl et., al. (2007) recorded patients admitted for illicit drug abuse overdose; on average 5.9 days. They added that, nearly 60 percent of the stays for illicit drug abuse originated in the emergency department, compared to (42.5) percent of all hospital stays. Jayakrishnan et., al. (2012) investigated adult patients admitted in the ICU of a tertiary hospital in Oman from January 2007 to December 2008 and they found that, opioids were the main illicit drugs abused by the patients who needed ICU care. 
The study also revealed that, there was significant difference between studied cases as regards clinical severity scoring presentations according to Persson et., al. (1998). Majority of severe cases were diagnosed as acute opiate and other opioids overdose $(33.3 \%)$ followed by those presented with acute tramadol overdose $(14.2 \%)$. There was any case presented with severe presentations diagnosed as pharmaceutical misused.

In-addition, Deaths recorded in the study complicating one third of methyl alcohol overdose cases followed by cases of acute tramadol and opiate and other opioids overdose. This goes parallel with the study of $\mathrm{Li}$ and Gunja, (2013) who investigated acute illicit drug overdose presentations referred to the Australian Poisons Information Centres. They found that the severe cases were mostly due to opioids overdose followed by stimulants and hypnotics like benzodiazepines. Rare severe manifestations were seen among those presented with cannabinoids overdose.

Halawa et. al., (2013) reported that the second cause of death among cases admitted to PCCASUH during 2012 was due to acute tramadol overdose. The life expectancy of injecting drug abusers after intensive care admission is substantially decreased, with $35 \%$ death rate as recorded in the study of Sigvaldason et., al. (2014) investigated injecting drug abuse cases admitted to emergency and ICU of Iceland hospitals.

In-contrary, El Masry and Tawfik (2013) showed that, the methanol poisoning mortality rate was decreased by about $75 \%$ due to the state's tighter control against alcoholic beverages adulteration.

The study also recorded that, there was significant difference between acute illicit drug abuse overdose cases regarding emergency treatment needed in the form of oxygen supply, endotracheal intubation (ETT), dopamine infusion and sedative hypnotic administration. Oxygen supply and endotracheal intubation were mostly needed in the emergency room among for cases of acute opiate and other opioids and tramadol overdose.

Moreover, majority of cases with acute opiate and other opioids and tramadol overdose mandated mechanical ventilation while half of methyl alcohol overdose and quarter of benzodiazepines cases needed mechanical ventilation. Dopamine infusion needed in majority of acute methyl alcohol intoxications followed by those presented with acute opiate and other opioids and tramadol overdose. Sedative hypnotics needed in half cases of acute tramadol overdose and majority of pharmaceutical misused cases.

Li and Gunja, (2013) stated that, among cases of illicit drug overdose, establishing a risk assessment alongside resuscitation are the first management priorities as well as sedation and assessment of neurological and cardiovascular risk.

Mokhlesi et., al. (2004) stated that, patients suffered from tramadol overdose are at particular risk, and indeed care must be taken with a multiplicity of drugs including sedatives and even immediate paralysis accompanied by sedation and ventilation in severe cases. Halawa et., al. (2013) showed that tramadol overdose cases showed second common drugs needed mechanical ventilation

Moreover, Devlin and Henry (2008) showed treatment needed for opiate and other opioids overdose. They showed that, respiratory depression with bradypnea and hypoxaemia caused by opioids overdose is straightforward managed by, first ensuring a patent airway and administering oxygen followed by naloxone or continued respiratory support. Li and Gunja, (2013) showed the treatment of cannabis which included reassurance, anti-emetics, titrated oral or IV benzodiazepines and anti-psychotics.

All previous clinical and management data concluded that drug abuse overdose is considered a valuable burden on the healthcare system. That was supported by the NIDA, (2010) reported, that illicit drug use and abuse may need specialized treatment, emergency department visits (sometimes involving death), contraction of illnesses, and prolonged hospital stays with negative consequences on society and economic burden on healthcare system.

\section{Conclusion and Recommendations}

This study showed that, Egypt community suffers from major problem of illicit drug abuse mainly among young adult males. The most available drug was tramadol followed by benzodiazepines, methyl alcohol, cannabis and opiate and other opioids. Female mostly abused pharmaceutical misused drug. Morbidities and mortalities showed that opiate and other opioids and tramadol represent the most severe cases that developed different forms of morbidities; cardiovascular, and neurological that mandated ICU admission. Moreover, methyl alcohol represented majority of cases suffered from metabolic morbidity as metabolic acidosis that needed longer hospital stay.

Most of deaths was diagnosed as acute opiate and other opioids overdose followed by those presented with tramadol and methyl alcohol overdose. As pattern of drug abuse is changeable from year to another and differs according to socio-demographic factors, more studies in Egypt are needed to be updated. These studies will help to predict the prognosis of such cases and to figure out the needs and hospital supplies as antidotes to be provided in poison control centers for treatment of such cases. Moreover, Egyptian street needs more banning program integrated between health, police and social 
ministries with other non-governmental agencies against drug abuse. Orientations campaigns for adolescents, young people at schools and universities needed to raise the awareness of the heath hazardous of illicit drug abuse.

\section{References}

Afifi M. (2007): "Gender differences in mental health". Sing Med J; 48 (5): 385.

Amr M. , El-GilanyA. , El-Mogy A., et., al. (2014): "Substance abuse and dependence among patients attending an emergency hospital in Eastern Nile delta, Egypt". J Psychiatry; 17:532-537.

Benyamin R., Trescot A.M., Datta S., et., al. (2008): "Opioid Complications and Side Effects". Pain Physician 2008: Opioid Special Issue: 11:S105-S120.

Boyer E.W. (2012): "Management of Opioid Analgesic Overdose". N. Engl. J. Med. Jul 12; 367(2): 146-155.

Brust J.C. (2014): "Neurologic complications of illicit drug abuse". Continuum (Minneap Minn). J. Neurology of Systemic Disease Jun; 20:642-56.

Cheryl A. Kassed C.A, Levit K.R.,. (2007): "Hospitalizations Related to Drug Abuse, 2005". Cited in http://www.hcup-us.ahrq.gov/reports/statbriefs/sb39.jsp.

Daubin C., Quentin C., Goullé J.P., et., al. (2007): "Refractory shock and asystole related to tramadol overdose". Clin Toxicol (Phila). Dec; 45(8):961-4.

Devlin R.J. and Henry J.A. (2008): "Clinical review: Major consequences of illicit drug consumption". Critical Care, 12:202.

Elkalioubie A., Allorge D., Robriquet L., et., al. (2011): "Near-fatal tramadol cardiotoxicity in a CYP2D6 ultrarapid metabolizer". Eur. J. Clin. Pharmacol. Aug; 67(8):855-8.

El MasryM.K., and Tawfik H. M. (2013): "2011 Annual Report of the Poison Control Centre of Ain Shams University Hospital, Cairo, Egypt". Ain Shams Journal of Forensic Medicine and Clinical Toxicology; 20: $10-17$

El-Sawy H., Abdel Hay M., and Badawy A. (2010): "Gender Differences in Risks and Pattern of Drug Abuse in Egypt". Egypt J Neurol Psychiat Neurosurg. Jan; Vol 47, Issue 1.

Fareed A., Stout S.J., Casarella S., et., al. (2011): "Illicit Opioid Intoxication: Diagnosis and Treatment". Substance Abuse: Research and Treatment; 5 17-25.
Fawzi M.M. (2011): “Some medicolegal aspects concerning tramadol abuse: The new Middle East youth plague 2010. An Egyptian overview”. Egyptian Journal of Forensic Sciences. 1: 99-102.

Greller H., and Gupta A. (2015): "Benzodiazepine poisoning and withdrawal". Cited in Uptodate, Sep. 2015.

Greenfield S.F., Back S.E., and Lawson K., et., al. (2010): "Substance abuse in women". Psychiatr. Clin. North Am; 33:339-55".

Halawa H. M., Nageeb S.A., Mahmoud Kh et. al., (2013): "Annual Report of the Poison Control Centre, Ain Shams University Hospitals -Cairo, Egypt, 2012". Ain Shams Journal of Forensic Medicine and Clin toxicol; Vol. 21:27-34

Henry J. A. (2000): "Metabolic consequences of drug misuse". Br J Anaesth; 85: 136-42.

Jann M., Kennedy W.K., and Lopez G. (2014): Benzodiazepines: a major component in unintentional prescription drug overdoses with opioid analgesics. J. Pharm. Pract. Feb. 27(1):5-16.

Jayakrishnan B., Al Asmi A., Al Qassabi A., et., al. (2012): "Acute Drug Overdose: Clinical Profile, Etiologic Spectrum and Determinants of Duration of Intensive Medical Treatment". Oman Medical Journal.Vol; 27, No. 6: 501-504.

Leffler A., Frank G., et., al. (2012): "Local anesthetic-like inhibition of voltage-gated $\mathrm{Na}(+)$ channels by the partial $\mu$-opioid receptor agonist buprenorphine. Anesthesiology. Jun; 116(6):1335-46.

Li W., and Gunja N. (2013): "Illicit drug overdose - prevalence and acute management". Clinical. Reprinted from Australian Family Physician Vol. 42, No. 6 , June.

Mokhlesi B., Garimella P.S., and Joffe A., et., al. (2004): "Street drug abuse leading to critical illness". Intensive Care Med, 30:1526- 1536.

NIDA, National Institute on Drug Abuse. (2010): "National Institute of Drug of Abuse: Impact of Drugs on Society".

NIDA, National Institute on Drug Abuse. (2011): "National Institute of Drug of Abuse to Announce Results of 2011 Monitoring the Future Survey". Dec. cited in http://www.drugabuse.gov/newsevents/news-releases/2011/12/national-institute-drugabuse-to-announce-results-2011-monitoring-futuresurvey. 
NIDA, National Institute on drug abuse. (2012):

"Cardiovascular Effects. In: Medical Consequences of Drug Abuse". Cited in http://www.drugabuse.gov/publications/medicalconsequences-drug abuse/cardiovascular-effects

NSDUH, National Survey on Drug Use and Health. (2010): "Mental Health Findings" cited in http://archive.samhsa.gov/data/NSDUH/2011SummNatFi ndDetTables/Index.aspx

Pateria P., de Boer B., and MacQuillan G. (2013): "Liver abnormalities in drug and substance abusers". Best Pract Res Clin Gastroenterol. Aug; 27(4):577-96.

Paulozzi L.J., Strickler G.K., Kreiner P.W., et., al. (2015): "Controlled Substance Prescribing Patterns Prescription Behavior Surveillance System, Eight States, 2013". MMWR Surveill Summ. 2015 Oct 16; 64(9):1-14.

Persson H., Sjöberg G., Haines J., et al., (1998): Poisoning severity score.

Roxburgh A., and Degenhardt L. (2006): "Hospital stays related to illicit drugs in Australia 19932004. NDAR C Technical Report Number 261". Sydney: National Drugs and Methyl alcohol Research Center, University of New South Wales, 2006.

SAMHSA, Substance Abuse and Mental Health Services Administration. (2013): “2013 National Survey on Drug Use and Health, Summary of National Findings". Cited in https://www.ruralhealthinfo.org/topics/substance-abuse.

Sharma R., Marasini S., Sharma A.K., et., al. (2011): "Methanol Poisoning: Ocular and Neurological Manifestations". Optom. Vis. Sci. Nov 28.

Shimane T., Matsumoto T., and Wada K. (2014): "Clinical behavior of Japanese community pharmacists for preventing prescription drug overdose". Psychiatry Clin Neurosci. Apr; 69(4):220-7.

Sigvaldason K., Ingvarsson T., Thordardottir S., et., al. (2014): "Injecting drug abuse: survival after intensive care admission and forensic toxicology reports at death". Laeknabladid. Oct; 100(10):515-9.

Swarnalatha G., Pai S., Ram R., and Dakshinamurty K.V. (2013): "Fulminant hepatic failure following marijuana drug abuse: Molecular adsorbent recirculation system therapy". Indian J Nephrol. Sep-Oct; 23(5): 384-386.
Sweileh W.M., Zyoud S.H., Al-Jabi S.W., and Sawalha A.F. (2014): "Substance use disorders in Arab countries: research activity and bibliometric analysis". Substance Abuse Treatment, Prevention, and Policy, 9:33.

Tait R.J., Caldicott D., Mountain D., et., al. (2015): "A systematic review of adverse events arising from the use of synthetic cannabinoids and their associated treatment". Clin Toxicol (Phila). 15:1-13.

Tashakori A., and Afshari R. (2010): "Tramadol overdose as a cause of serotonin syndrome: a case series”. Clin Toxicol (Phila). May; 48(4):337-41.

Tawfik H., and ElHelaly H. (2015): "Toxicological Profile of Acutely Poisoned cases Admitted to Poison Control Center, Ain-Shams University Hospitals". Ain Shams Journal of Forensic Medicine and Clinical Toxicology. Jan; 24: 154-163.

UNAIDS, United Nations Program on HIV/AIDS. (2004): “epidemiological fact sheet". A Joint United Nations Program on HIV/AIDS. Cited in http://data.unaids.org/publications/factsheets01/egypt_en.pdf.

UNODC, UNITED NATIONS OFFICE ON DRUGS AND CRIME. (2011): "World Drug Report 2011". Cited in https://www.unodc.org/documents/dataand-

analysis/WDR2011/World_Drug_Report_2011_ebook.p df.

UNODC, UNITED NATIONS OFFICE ON DRUGS AND CRIME. (2014): "World Drug Report 2014". Cited in https://www.unodc.org/documents/dataand-

analysis/WDR2011/World_Drug_Report_2011_ebook.p df.

Vengeliene V. Bilbao A., Molander A. et., al. (2008). "Neuropharmacology of alcohol addiction". British Journal of Pharmacology 154 (2): 299-315.

Verhelst D., Moulin P., Haufroid V., et., al. (2004): "Acute Renal Injury Following Methanol Poisoning: Analysis of a CaseSeries". International Journal of Toxicology, 23: 267-273.

WHO, (2014): “Tramadol Update Review
Cited http://www.who.int/medicines/areas/quality_safety/6_1_ Update.pdf. 


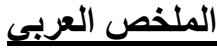

دراسة مقارنة للأعتلال والوفيات بين الحالات التي عانت من جرعات زائدة من الأنواع المختلفة من المواد المخدرة

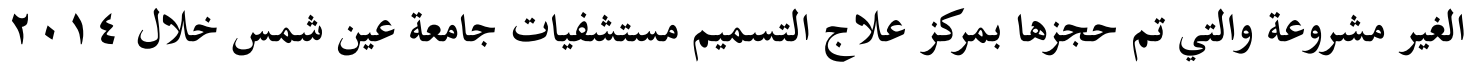

د. هند الهلالي' و د. هاني توفيق ب واحمد شعبانץ

مقدمة:المعلومات الجحديدة المتعلقة بمدي انتشارية المواد المخدرة غير المشروعة علي مستوي العالم محدودة واتي بدورها تعتبر مشكلة طبية كبيرة. الهدف من الدراسة:هدف الدراسة إلى معرفة مدى انتشار ظاهرة تعاطي المخدرات الغير مشروعة في القاهرة القاهرة مصر

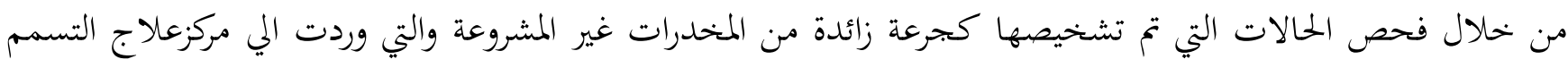

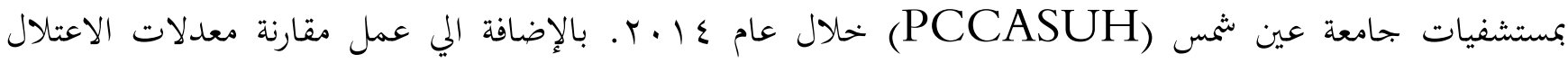

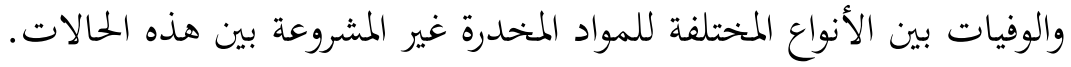

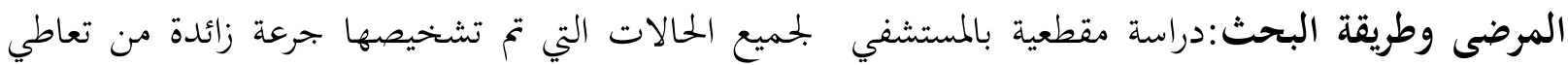

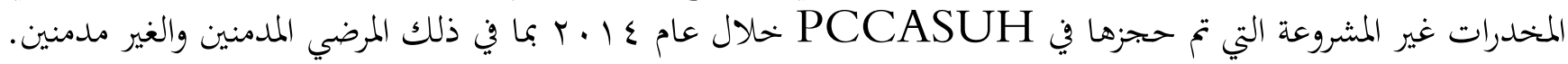

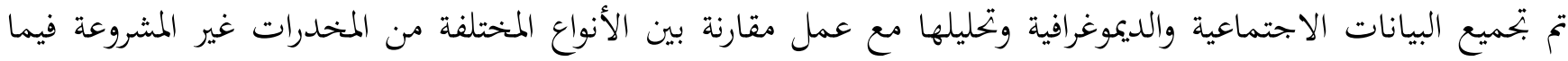

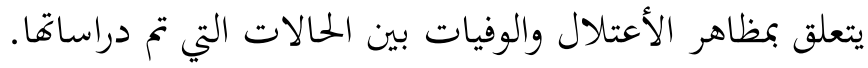

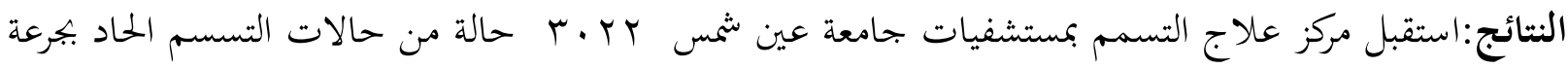

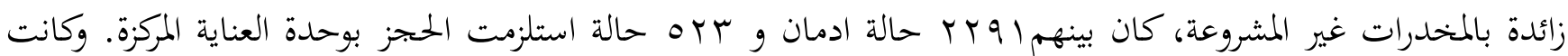

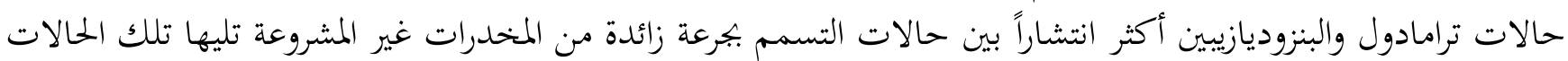

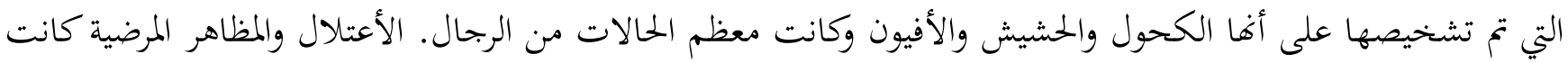

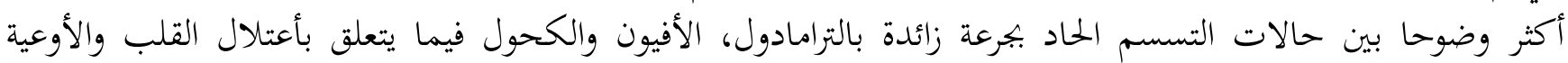

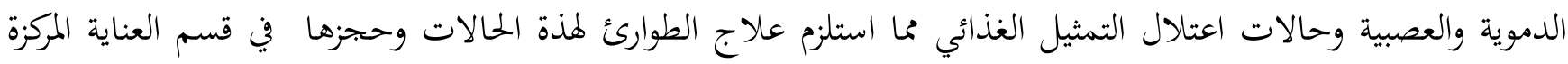
(ICU)

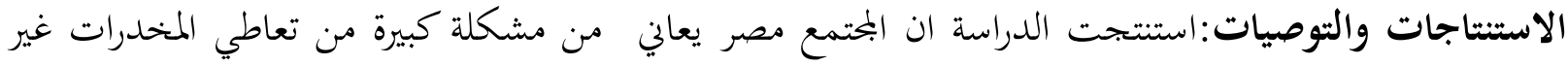

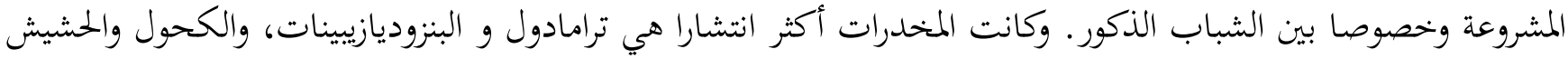

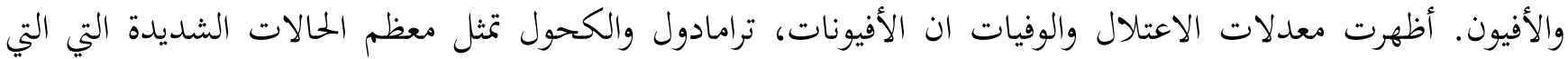

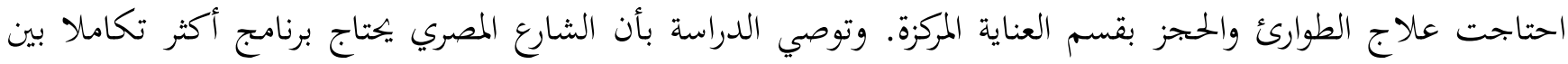

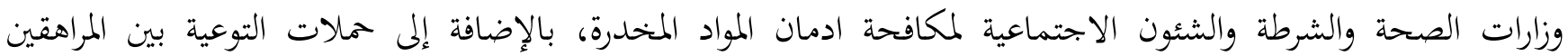
والشباب في النوادي والمدارس والحامعات. 